\title{
Mindfulness-and body-psychotherapy-based group treatment of chronic tinnitus: a randomized controlled pilot study
}

Peter M Kreuzer*, Monika Goetz, Maria Holl, Martin Schecklmann, Michael Landgrebe, Susanne Staudinger and Berthold Langguth

\begin{abstract}
Background: Tinnitus, the perception of sound in absence of an external acoustic source, impairs the quality of life in $2 \%$ of the population. Since in most cases causal treatment is not possible, the majority of therapeutic attempts aim at developing and strengthening individual coping and habituation strategies. Therapeutic interventions that incorporate training in mindfulness meditation have become increasingly popular in the treatment of stress-related disorders. Here we conducted a randomized, controlled clinical study to investigate the efficacy of a specific mindfulness- and body-psychotherapy based program in patients suffering from chronic tinnitus.
\end{abstract}

Methods: Thirty-six patients were enrolled in this pilot study. The treatment was specifically developed for tinnitus patients and is based on mindfulness and body psychotherapy. Treatment was performed as group therapy at two training weekends that were separated by an interval of 7 weeks (eleven hours/weekend) and in four further two-hour sessions (week 2, 9, 18 and 22). Patients were randomized to receive treatment either immediately or after waiting time, which served as a control condition. The primary study outcome was the change in tinnitus complaints as measured by the German Version of the Tinnitus Questionnaire (TQ).

Results: ANOVA testing for the primary outcome showed a significant interaction effect time by group ( $F=7.4$; $\mathrm{df}=1,33 ; \mathrm{p}=0.010$ ). Post hoc t-tests indicated an amelioration of TQ scores from baseline to week 9 in both groups (intervention group: $t=6.2 ; \mathrm{df}=17 ; \mathrm{p}<0.001$; control group: $\mathrm{t}=2.5 ; \mathrm{df}=16 ; \mathrm{p}=0.023$ ), but the intervention group improved more than the control group. Groups differed at week 7 and 9, but not at week 24 as far as the TQ score was concerned.

Conclusions: Our results suggest that this mindfulness- and body-psychotherapy-based approach is feasible in the treatment of tinnitus and merits further evaluation in clinical studies with larger sample sizes.

The study is registered with clinicaltrials.gov (NCT01540357).

Keywords: Subjective tinnitus, Mindfulness-based therapy, Somatoform disorders, Self-management

\section{Background}

Tinnitus is defined as the perception of sound in the absence of an external sound source. About one in 10 adults is affected by chronic tinnitus, 20-30 percent of them dealing with considerable effects on daily living [1]. Severe tinnitus is frequently related to comorbidities such as insomnia [2], somatoform disorders, depression [3] or anxiety [4,5]. There have not been many effective

\footnotetext{
* Correspondence: peter.kreuzer@medbo.de

Department of Psychiatry and Psychotherapy, University of Regensburg, Universitaetsstrasse 84, Regensburg 93053, Germany
}

treatment options up to now [6]. The best evidence is available for cognitive behavioral therapy so far, which aims to facilitate habituation by improving individual tinnitus coping strategies [6-8].

Mindfulness-based approaches use meditation techniques and yoga-like elements, and were introduced to clinical medicine about thirty years ago [9]. They have demonstrated efficacy in the treatment of a variety of stress-related disorders [10,11] such as anxiety and mood disorders [12] or chronic pain [13,14]. Very recently, mindfulness-based cognitive therapy has been 
proposed for the treatment of tinnitus [15-18]. Mindfulness also constitutes an integral element of the cognitive behavioral treatment programs for tinnitus that have shown convincing results in this indication so far $[17,18]$.

In the current randomized waiting-list-controlled pilot study, we investigated a new manualized therapeutic approach, which is based on mindfulness- and bodypsychotherapy and which has been specifically developed for the treatment of tinnitus patients (Tinnitus Atemtherapie) [19]. Essential components of the treatment program include mindfulness, meditation, selfmassage, and breathing exercises. These components are intended to help patients use their inner resources to accept responsibility for themselves, become more self-sufficient and develop symptom acceptance.

\section{Methods}

\section{Patient recruitment}

Thirty-six patients with chronic tinnitus (duration $\geq$ 6 months) were randomized in an experimental group or a waiting list control group of 18 subjects, each after giving written, informed consent to the study. Randomization was conducted applying a computer-generated random list. Clients were recruited by direct referral from a local ENT physician and by an advertisement in the newsletter of the German Tinnitus League. The study was approved by the local ethics committee of the University of Regensburg, Germany (Ethikkommission der Fakultät für Medizin der Universität Regensburg). The study is registered with clinicaltrials.gov (NCT01540357).

\section{Study design}

Inclusion criteria were 1) age between 18 and 80 years 2) location in the north-western part of Germany or in Belgium and the ability to understand the German language 3) no communicational problems 4) individual burden caused by subjective tinnitus for at least 6 months and 5) absence of any instable medical conditions. The experimental group was treated with the manualized group therapy; the control group was assessed at the identical time points during a waiting period of 24 weeks before they received treatment. No changes to methods and outcome measures were made after the trial began. Demographical and clinical characteristics of the enrolled patients are provided in Table 1.

Table 1 Sample characteristics for the whole group and statistical parameters (mean \pm standard deviation)

\begin{tabular}{|c|c|c|c|}
\hline & Intervention group & Control group & Statistics \\
\hline$n$ & 18 & 18 & \\
\hline gender (male/ female) & $11 / 7$ & $8 / 10$ & $x^{2}=1.0 ; d f=1 ; p=0.317$ \\
\hline age & $49.6 \pm 8.8$ & $51.7 \pm 16.0$ & $t=0.5 ; d f=34 ; p=0.629$ \\
\hline tinnitus duration & $100.5 \pm 119.1$ & $142.3 \pm 116.2$ & $t=1.1 ; d f=33 ; p=0.300$ \\
\hline number of previous treatments & $3.4 \pm 2.0$ & $3.7 \pm 2.1$ & $t=0.5 ; d f=33 ; p=0.653$ \\
\hline laterality (left, both/central, right) & $6,6,5$ & $8,3,7$ & $x^{2}=1.6 ; d f=2 ; p=0.451$ \\
\hline \multicolumn{4}{|l|}{ Questionnaires } \\
\hline Tinnitus Questionnaire & $34.1 \pm 15.8$ & $37.4 \pm 14.9$ & $t=0.7 ; d f=34 ; p=0.512$ \\
\hline Tinnitus Handicap Inventory & $41.0 \pm 20.4$ & $45.9 \pm 17.7$ & $\mathrm{t}=0.8 ; \mathrm{df}=34 ; \mathrm{p}=0.448$ \\
\hline Beck Depression Inventory & $11.1 \pm 8.1$ & $11.8 \pm 7.0$ & $t=0.3 ; d f=34 ; p=0.793$ \\
\hline \multicolumn{4}{|l|}{ Numeric rating scales } \\
\hline loudness & $5.7 \pm 2.5$ & $6.5 \pm 2.2$ & $t=1.0 ; d f=34 ; p=0.328$ \\
\hline annoyance & $7.2 \pm 2.3$ & $5.9 \pm 3.0$ & $t=1.4 ; d f=33 ; p=0.158$ \\
\hline discomfort & $6.9 \pm 2.8$ & $7.3 \pm 2.3$ & $\mathrm{t}=0.5 ; \mathrm{df}=34 ; \mathrm{p}=0.600$ \\
\hline distractibility & $6.2 \pm 2.7$ & $6.4 \pm 2.7$ & $t=0.3 ; d f=34 ; p=0.806$ \\
\hline unpleasantness & $5.9 \pm 2.8$ & $7.1 \pm 2.2$ & $t=1.4 ; d f=34 ; p=0.169$ \\
\hline \multicolumn{4}{|l|}{ Other (no, yes) } \\
\hline temporomandibular joint disorder & 12,5 & 14,4 & $x^{2}=0.2 ; d f=1 ; p=0.627$ \\
\hline neck pain & 7,10 & 6,12 & $x^{2}=0.2 ; d f=1 ; p=0.631$ \\
\hline other pain & 10,6 & 10,8 & $x^{2}=0.2 ; d f=1 ; p=0.681$ \\
\hline influence of neck movement & 12,4 & 9,9 & $x^{2}=2.2 ; d f=1 ; p=0.134$ \\
\hline psychiatric comorbidity & 12,5 & 14,4 & $x^{2}=0.2 ; d f=1 ; p=0.627$ \\
\hline
\end{tabular}




\section{Treatment program}

The treatment program includes mindfulness, meditation, self-massage, and breathing exercises as the main components and was developed and manualized [19] by one of the authors $(\mathrm{MH}) . \mathrm{MH}$ is an experienced therapist with a focus on stress-related disorders and also conducted the therapeutic meetings in Aachen, Germany.

Briefly, the treatment consists of (1) meditation elements, (2) imagination exercises, (3) self-massage and individualized gentle movement exercises of the body, (4) exercises aiming at directing moment-to-moment awareness of body- and self- perception and (5) breathing exercises with emphasis on expiration in order to reduce muscle tension and increase relaxation. Participants were taught the therapeutic modules at two weekends ( 11 hours of treatment/weekend) with an interval of 7 weeks. Two weeks after each weekend and 11 and 15 weeks after the second training weekend patients gathered for a review meeting lasting 2 hours each. Patients were strongly encouraged to perform exercises themselves regularly and were instructed to contact and motivate each other by telephone at least once a week. Data assessment and analysis took place at the University of Regensburg, Regensburg, Germany.

\section{Assessment instruments and statistical analysis}

Tinnitus characteristics were assessed before treatment (baseline), at week 7 (end of second training weekend), at week 9 and week 24 (Figure 1). Tinnitus assessments included the German versions of the Tinnitus Handicap Inventory [20], the Tinnitus Questionnaire [21], the Beck Depression Inventory [22], several tinnitus numeric rating scales (loudness, discomfort, annoyance, distractibility, unpleasantness) [23]. Prospective assessment of treatment effects was performed using standardized procedures as established in the Tinnitus Research Initiative (TRI) database [23]. Data management was conducted according to the Data Handling Plan (TRIDHP Version 06, May $\left.9^{\text {th }}, 2011\right)$. Data analysis was conducted according to the Standard Operating Procedure (TRI-SA Version 01, May $9^{\text {th }}, 2011$ ), which followed a study-specific Statistical Analysis Plan (SAP-002). All documents are to be found under http://database. tinnitusresearch.org/.

The primary outcome was the change in TQ scores from baseline to week 9. For this purpose, we conducted an analysis of variance (ANOVA) with the withinsubjects factor time (screening and week 9) and the between-subjects factor group (intervention vs. control group). Repeated measures ANOVA as used in this study may be confounded with several issues, i.e., low statistical power, regression to the mean due to baseline differences, inflation of type I error due to multiple post hoc tests, etc. [24-26]. Thus, we controlled for these issues by repeating the primary outcome analysis by calculating an ANCOVA with the between-subjects factor group (intervention vs. control group), with the baseline values of the TQ as covariate, and with TQ score at week 9 as dependent variable. Regression slopes between the covariate and the dependent variable were comparable across conditions (0.848 and 0.864$)$. Secondary outcome measures included chi-square tests for the variables group and treatment response, which was defined as amelioration of at least 5 points in the TQ [27]. In addition, we conducted an additional ANOVA with the factor group and time, this time including four measurement time points (screening, week7, week 9, and week 24). For THI, the numeric rating scales and BDI we performed identical ANOVAs.

\section{Results}

The trial was conducted and terminated according to the study protocol priorily defined. No adaption was necessary during the course of the study (April 2010 to December 2010). The groups did not differ significantly in demographical or clinical characteristics as shown in Table 1.

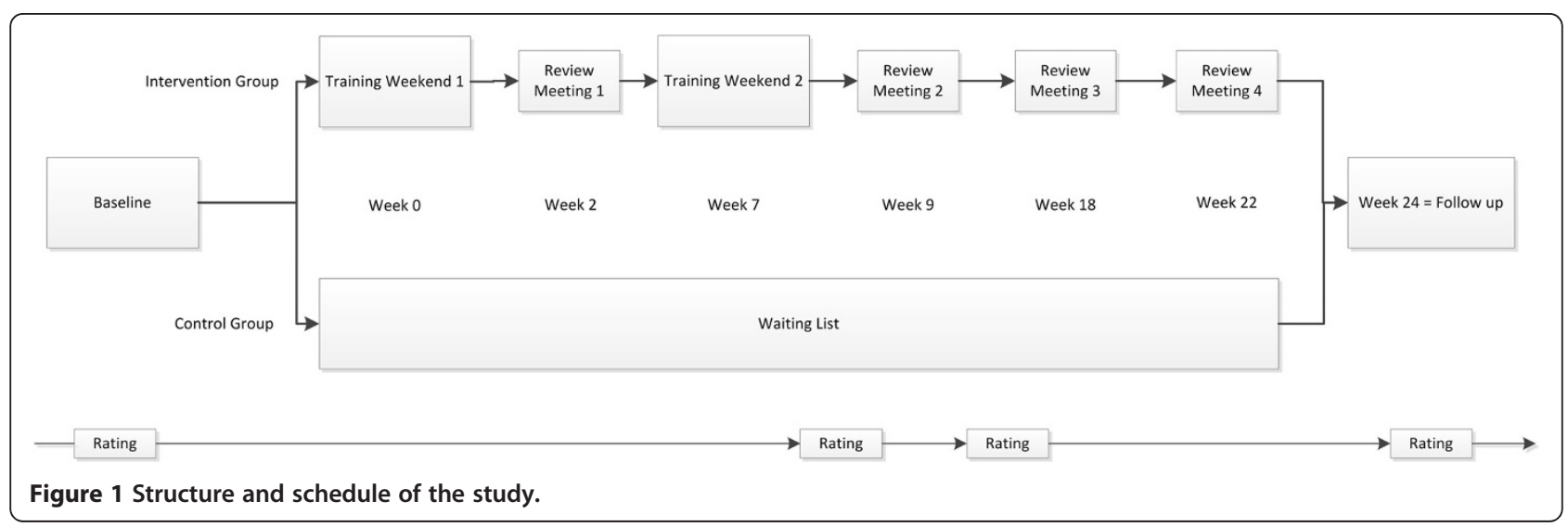


Three participants did not complete the study procedures. One patient refused to participate after being randomized into the waiting list group; two patients did not return the follow-up-questionnaires after having participated in the meetings without giving any further explanation. These three patients were excluded from our analysis.

ANOVA testing for primary outcome demonstrated a significant interaction effect time by group $(\mathrm{F}=7.4 ; \mathrm{df}=$ 1,$\left.33 ; \mathrm{p}=0.010 ; \eta^{2}=0.183\right)$. Post hoc $\mathrm{t}$-tests indicated an amelioration of TQ scores from baseline to week 9 in both groups (intervention group: $\mathrm{t}=6.2 ; \mathrm{df}=17$; $\mathrm{p}<0.001$; $\mathrm{d}=1.458$; control group: $\mathrm{t}=2.5 ; \mathrm{df}=16 ; \mathrm{p}=0.023 ; \mathrm{d}=$ 0.611 ) (Figure 2), but the intervention group improved at a higher rate than the control group (baseline: $\mathrm{t}=0.7 ; \mathrm{df}=$ $31 ; \mathrm{p}=0.480 ; \mathrm{d}=0.249$; week 9: $\mathrm{t}=2.2 ; \mathrm{df}=31 ; \mathrm{p}=0.036$; $\mathrm{d}=0.764$ ). To account for potential statistical bias (see methods) we redid the primary outcome analysis with an ANCOVA using the baseline values as covariate and TQ score as single dependent variable. Group main effect was again significant $\left(\mathrm{F}=10.948 ; \mathrm{df}=1,32 ; \mathrm{p}=0.002 ; \eta^{2}=\right.$ $0.255)$. The responder rate was higher in the intervention group (14 responders out of 16 subjects) compared to the control group ( 8 responders out of 17 subjects; $\chi^{2}=6.1$; $\mathrm{df}=1 ; \mathrm{p}=0.014)$ with an odds ratio of 7.9 (CI: 1.4-45.8) and a relative risk of 3.5 (CI: 1.0-12.8).

ANOVA with four measurement time points showed a nearly significant interaction effect time by group ( $\mathrm{F}=$ 2.2 ; df $\left.=3,93 ; \mathrm{p}=0.094 ; \eta^{2}=0.066\right)$. Post hoc tests indicated a significant amelioration at week 7 , week 9 , and week 24 in contrast to baseline for the intervention group (all ts $>3.1$; df $=15$; all $\mathrm{ps}<0.008$; all $\mathrm{ds}>0.766$ ) and at week 9 and 24 for the control group in contrast to baseline (all ts $>2.5$; $\mathrm{df}=16$; all $\mathrm{ps}<0.023$; all $\mathrm{ds}>$ $0.611)$. The groups differed at week $7(t=1.8 ; \mathrm{df}=31$; $\mathrm{p}=0.077 ; \mathrm{d}=0.638$ ) and 9 (see primary outcome), but not at week 24 ( $\mathrm{t}=1.2 ; \mathrm{df}=31 ; \mathrm{p}=0.257 ; \mathrm{d}=0.402)$.
Concordant effects were also found for THI and BDI (see Table 2). Numeric rating scales did not show significant interaction effects (see Table 2). Means and standard deviations are provided for all measurements and assessment points in Table 2.

The responder rate at week 24 was not statistically higher in the intervention group (11 responders out of 16 subjects) compared to the control group (10 responders out of 17 subjects; $x^{2}=0.4 ; \mathrm{df}=1 ; \mathrm{p}=0.554$ ) with an odds ratio of 1.5 (CI: 0.4-6.5) and a relative risk of 1.3 (CI: 0.6-2.8).

\section{Discussion}

The main finding of this pilot study was a significant reduction in the TQ score (baseline vs. week 9) after thirty hours of this new manualized group therapy compared to the waiting list control group. Very recently, first results were presented from a randomized controlled study investigating mindfulness-based therapy in tinnitus patients [16]. Notably, in this previous study neither mindfulness-based therapy nor relaxation training as a control condition exerted an immediate effect on tinnitus symptoms. This might at least in part be due to the large effect already yielded by the preceding psychoeducation [16]. However, during the follow-up period mindfulness-based treatment was superior to relaxation therapy [16].

In contrast to this previous study [16], progress tended to stagnate in our study. Clearly, mindfulness-based therapy depends on practice behavior [16]. Thus, the retrogressive effects in our study point to a reduced training maintenance at follow-up and may indicate the relevance of boosting sessions for stabilizing treatment effects.

A pronounced long-lasting effect was also observed in a randomized, controlled study treating chronic tinnitus with a training program lasting five weeks with Qigong

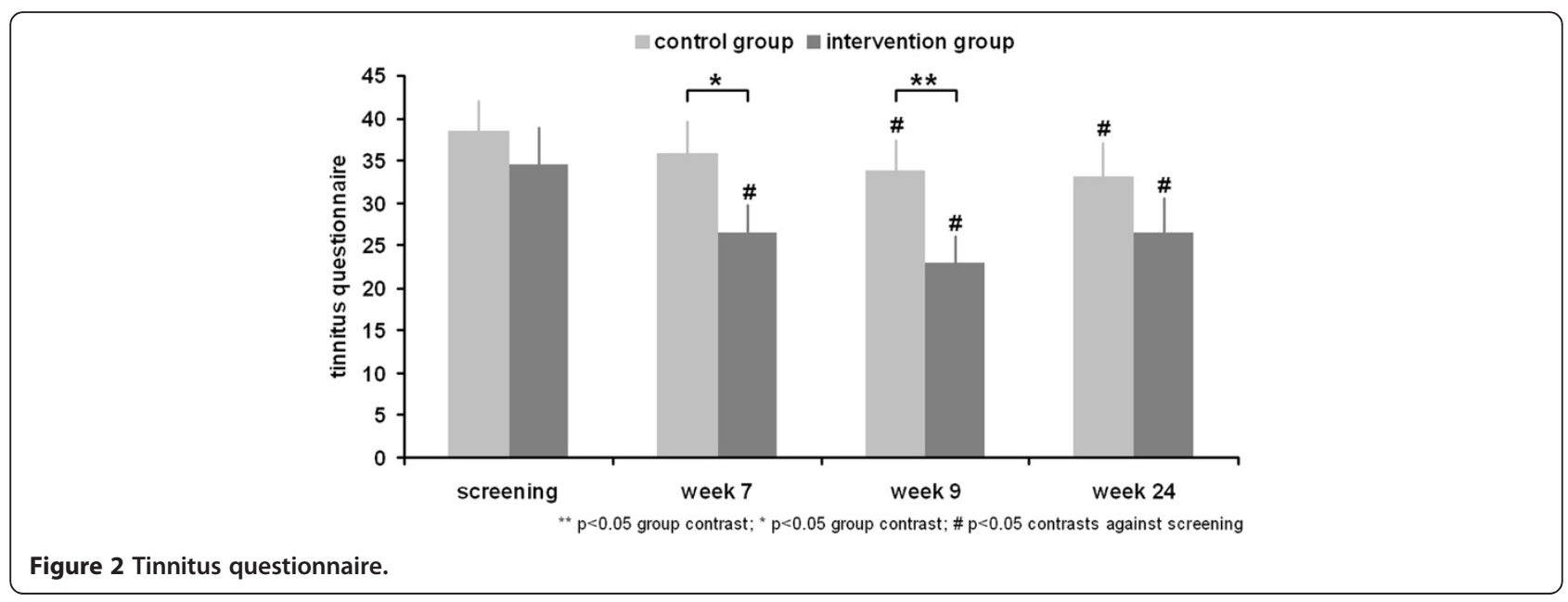


Table 2 Sample characteristics over all measurement time points and statistical parameters (mean \pm standard deviation); n.d. = not done

$\begin{array}{llll}\begin{array}{l}\text { Intervention } \\ \text { group }(d f=15)\end{array} & \begin{array}{l}\text { Control } \\ \text { group }(d f=16)\end{array} & \begin{array}{l}\text { Intervention vs. } \\ \text { control group } \\ (d f=31)\end{array} & \begin{array}{l}\text { Time by group } \\ \text { interaction } \\ \text { effect }(d f=3,93)\end{array}\end{array}$

\section{Questionnaires}

Tinnitus Questionnair

screening

week 7

week 9

week 24

week 7 vs. baseline

week 9 vs. baseline

week 24 vs. baseline

Tinnitus Handicap Inventory

\section{screening}

week 7

week 9

week 24

week 7 vs. baseline

week 9 vs. baseline

week 24 vs. baseline

Beck Depression Inventory

\section{screening}

week 7

week 9

week 24

week 7 vs. baseline

week 9 vs. baseline

week 24 vs. baseline

Numeric rating scales

\begin{tabular}{|c|c|c|c|c|c|}
\hline \multirow[t]{7}{*}{ loudness } & screening & $5.9 \pm 2.5$ & $6.7 \pm 2.1$ & n.d. & \multirow[t]{7}{*}{$F=1.9 ; p=0.135$} \\
\hline & week 7 & $5.3 \pm 2.8$ & $6.6 \pm 2.4$ & n.d. & \\
\hline & week 9 & $5.1 \pm 2.6$ & $6.8 \pm 2.1$ & n.d. & \\
\hline & week 24 & $5.1 \pm 2.7$ & $7.0 \pm 2.3$ & n.d. & \\
\hline & week 7 vs. baseline & n.d. & n.d. & & \\
\hline & week 9 vs. baseline & n.d. & n.d. & & \\
\hline & week 24 vs. baseline & n.d. & n.d. & & \\
\hline \multirow[t]{7}{*}{ annoyance } & screening & $6.2 \pm 3.1$ & $7.4 \pm 2.3$ & $t=1.3 ; p=0.225$ & \multirow[t]{7}{*}{$F=2.3 ; p=0.087$} \\
\hline & week 7 & $5.0 \pm 2.7$ & $6.9 \pm 2.4$ & $\mathrm{t}=2.2 ; \mathrm{p}=0.037$ & \\
\hline & week 9 & $4.6 \pm 2.2$ & $7.4 \pm 2.1$ & $t=3.6 ; p=0.001$ & \\
\hline & week 24 & $5.4 \pm 2.6$ & $7.2 \pm 2.5$ & $t=2.1 ; p=0.045$ & \\
\hline & week 7 vs. baseline & $\mathrm{t}=-2.3 ; \mathrm{p}=0.037$ & $t=-1.6 ; p=0.110$ & & \\
\hline & week 9 vs. baseline & $\mathrm{t}=-2.5 ; \mathrm{p}=0.025$ & $t=0$ & & \\
\hline & week 24 vs. baseline & $\mathrm{t}=-1.5 ; \mathrm{p}=0.154$ & $t=-0.4 ; p=0.683$ & & \\
\hline \multirow[t]{5}{*}{ discomfort } & screening & $7.1 \pm 2.8$ & $7.6 \pm 2.0$ & n.d. & \multirow[t]{5}{*}{$F=1.9 ; p=0.142$} \\
\hline & week 7 & $5.3 \pm 2.8$ & $7.1 \pm 2.3$ & n.d. & \\
\hline & week 9 & $5.5 \pm 2.7$ & $7.4 \pm 1.8$ & n.d. & \\
\hline & week 24 & $5.6 \pm 2.9$ & $7.3 \pm 1.9$ & n.d. & \\
\hline & week 7 vs. baseline & n.d. & n.d. & & \\
\hline
\end{tabular}

$34.6 \pm 16.7 \quad 38.5 \pm 14.7 \quad \mathrm{t}=0.7 ; \mathrm{p}=0.480 \quad \mathrm{~F}=2.2 ; \mathrm{p}=0.094$

$26.4 \pm 13.6$

$35.8 \pm 15.5$

$t=1.8 ; p=0.077$

$22.9 \pm 13.0$

$33.7 \pm 15.2$

$t=2.2 ; p=0.036$

$26.5 \pm 16.3$

$33.1 \pm 16.6$

$t=1.2 ; p=0.257$

$t=-4.3 ; p<0.001$

$t=-1.4 ; p=0.182$

$t=-5.4 ; p<0.001$

$t=-2.5 ; p=0.023$

$t=-3.1 ; p=0.008$

$t=-2.7 ; p=0.015$

$40.9 \pm 21.7 \quad 47.1 \pm 17.5$

$T=0.9 ; p=0.373$

$F=4.4 ; p=0.006$

$29.3 \pm 17.1$

$44.8 \pm 19.9$

$\mathrm{T}=2.4 ; \mathrm{p}=0.022$

$26.3 \pm 17.4$

$41.4 \pm 20.0$

$\mathrm{T}=2.3 ; p=0.027$

$27.3 \pm 19.9$

$41.3 \pm 21.1$

$T=2.0 ; p=0.058$

$\mathrm{t}=-4.2 ; \mathrm{p}<0.001$

$\mathrm{t}=-1.3 ; p=0.225$

$t=-7.4 ; p<0.001$

$\mathrm{t}=-3.3 ; \mathrm{p}=0.004$

$\mathrm{t}=-5.5 ; \mathrm{p}<0.001$

$t=-2.3 ; p=0.037$

$11.4 \pm 8.4$

$12.3 \pm 6.9$

$t=0.4 ; p=0.732$

$F=4.4 ; p=0.006$

$8.7 \pm 7.6$

$12.5 \pm 6.6$

$t=1.5 ; p=0.135$

$6.3 \pm 4.8$

$12.1 \pm 6.7$

$t=2.9 ; p=0.007$

$7.6 \pm 5.7$

$13.3 \pm 8.7$

$t=2.2 ; p=0.035$

$t=-2.6 ; p=0.019$

$t=0.4 ; p=0.718$

$t=-3.8 ; p=0.002$

$\mathrm{t}=-0.2 ; p=0.841$

$t=-2.5 ; p=0.024$

$t=0.8 ; p=0.455$ 
Table 2 Sample characteristics over all measurement time points and statistical parameters (mean \pm standard deviation); n.d. = not done (Continued)

\begin{tabular}{|c|c|c|c|c|c|}
\hline & week 9 vs. baseline & n.d. & n.d. & & \\
\hline & week 24 vs. baseline & n.d. & n.d. & & \\
\hline \multirow[t]{7}{*}{ distractibility } & screening & $6.4 \pm 2.8$ & $6.6 \pm 2.6$ & n.d. & $F=1.9 ; p=0.132$ \\
\hline & week 7 & $5.7 \pm 3.0$ & $6.8 \pm 3.1$ & n.d. & \\
\hline & week 9 & $5.3 \pm 2.8$ & $7.2 \pm 2.1$ & n.d. & \\
\hline & week 24 & $5.6 \pm 2.7$ & $7.2 \pm 2.8$ & n.d. & \\
\hline & week 7 vs. baseline & n.d. & n.d. & & \\
\hline & week 9 vs. baseline & n.d. & n.d. & & \\
\hline & week 24 vs. baseline & n.d. & n.d. & & \\
\hline \multirow[t]{7}{*}{ unpleasantness } & screening & $6.2 \pm 2.8$ & $7.0 \pm 2.2$ & n.d. & $F=1.1 ; p=0.370$ \\
\hline & week 7 & $5.4 \pm 2.7$ & $6.9 \pm 2.5$ & n.d. & \\
\hline & week 9 & $5.4 \pm 2.5$ & $7.0 \pm 2.2$ & n.d. & \\
\hline & week 24 & $5.4 \pm 2.4$ & $7.4 \pm 2.0$ & n.d. & \\
\hline & week 7 vs. baseline & n.d. & n.d. & & \\
\hline & week 9 vs. baseline & n.d. & n.d. & & \\
\hline & week 24 vs. baseline & n.d. & n.d. & & \\
\hline
\end{tabular}

[28]. Notably, Qigong had been trained in sessions of 2 hours weekly and one could question the time schedule of two weekends of intensive training of up to 11 hours in our study. Possibly a longer-lasting and repetitive training process would enhance longer-lasting effects through better incorporation of the exercises into daily routine.

Mindfulness-based therapeutic approaches have demonstrated beneficial effects in other stress-related disorders such as chronic pain [13,29] or anxiety [12]. With effect sizes of 0.37 for pain scores [29] and between 0.24 to 0.47 on anxiety scores in patients with chronic medical diseases [10], the effects of mindfulness-based therapies were smaller in those studies when compared to the effect size of 0.80 in our study. However caution is warranted in such comparisons, since further data from larger samples will be needed before the effect size of mindfulness- and bodypsychotherapy based treatment in tinnitus can be reliably estimated.

Future studies should also address the specific relevance of the different therapeutic components and their potential neurobiological mechanisms. A significant increase in alpha power through meditation has been revealed by electroencephalographic [30] and magnetencephalographic [31] studies. Alpha power in sensory areas is considered an indicator of inhibitory function [32] and an increase of alpha activity by neurobiofeedback or transcranial magnetic stimulation has been shown to result in reduced tinnitus perception $[33,34]$. Thus it is tempting to speculate that the beneficial effects of mindfulness- and meditation- based therapy may be mediated by an increase in alpha power. Moreover, brain areas which are known to be involved in tinnitus such as the left hippocampus [35], the posterior cingulate cortex [36], the temporo-parietal junction [37], and the cerebellum [38] have recently been shown to be altered by mindfulness meditation [39].

From a psychological point of view, few studies have focused on the potential mechanisms of mindfulness and acceptance-based training procedures in tinnitus patients, unfortunately. It has been proposed that mindfulness based therapy can facilitate adaptive responses by enhancing cognitive defusion strategies and symptom acceptance connected with a non-evaluative observation of internal events. For example, in a sample of 19 tinnitus patients the frequency of cognitive defusion behaviors and peak level of cognitive defusion as well as peak level of acceptance rated in session 2, predicted a symptom reduction 6 months following treatment, indicating that clients' in-session acceptance and cognitive defusion behaviors appear to play an important role in the reduction of the negative impact of tinnitus [7].

\section{Conclusions}

We are well aware of the limiting factors of the pilot study conducted, such as the small sample size, the inherent problems of waiting-list control conditions [40], and the fact that treatment effects may depend on the instructor, which might limit generalization of the results. Nevertheless our pilot data indicate the promise of mindfulnessand body-psychotherapy-based therapy in the treatment of tinnitus and warrant further investigation of its clinical and neurobiological effects in larger studies. 


\section{Competing interests}

MH has written the treatment manual for "Tinnitus Atemtherapie" and offers this treatment in private practice. MH has been supported by a grant from the Bundesverband der Innungskrankenkassen (IKK), Association of Health Insurances. The other authors declare no competing interests in relation to this article.

\section{Authors' contributions}

PK, SS; ML, MS and BL designed the study. MG and MH were responsible for the generation of the patients' enrollment, randomized assignment of participants to the interventions and the practical conduction of participants training. SS and MG were responsible for data management and data entry in the TRI database. MS was responsible for statistical analysis. PK, MG, MS and BL drafted the manuscript. All authors approved the final version of the manuscript. For full trial protocol please contact the corresponding author.

\section{Financial disclosure}

$\mathrm{MH}$ has written a book describing the methods of the applied behavioral techniques. The study has been financially supported by a grant from the Bundesverband der Innungskrankenkassen (IKK), Association of Health Insurances. The other authors have no conflicts of interest or disclosures to declare in relation to this article.

\section{Acknowledgements}

The authors were supported by a grant from the Tinnitus Research Initiative (TRI) to the Tinnitus Research Initiative Database.

Received: 10 June 2012 Accepted: 24 November 2012

Published: 28 November 2012

\section{References}

1. Andersson G, Baguley D, McKenna L: Tinnitus: A Multidisciplinary Approach. London: Whurr; 2005.

2. Cronlein T, Langguth B, Geisler P, Hajak G: Tinnitus and insomnia. Prog Brain Res 2007, 166:227-233.

3. Langguth B, Landgrebe M, Kleinjung T, Sand GP, Hajak G: Tinnitus and depression. World J Biol Psychiatry 2011, 12(7):489-500. Epub 2011 May 13.

4. Langguth B: A review of tinnitus symptoms beyond 'ringing in the ears': a call to action. Curr Med Res Opin 2011, 27:1635-1643.

5. Krog NH, Engdahl B, Tambs K: The association between tinnitus and mental health in a general population sample: results from the HUNT Study. J Psychosom Res 2010, 69(3):289-298. Epub 2010 Apr 21.

6. Hoare DJ, Kowalkowski VL, Kang S, Hall DA: Systematic review and meta-analyses of randomized controlled trials examining tinnitus management. Laryngoscope 2011, 121:1555-1564.

7. Hesser H, Westin V, Hayes SC, Andersson G: Clients' in-session acceptance and cognitive defusion behaviors in acceptance-based treatment of tinnitus distress. Behav Res Ther 2009, 47:523-528.

8. Martinez-Devesa P, Perera R, Theodoulou M, Waddell A: Cognitive behavioural therapy for tinnitus. Cochrane Database Syst Rev 2010 8(9):CD005233.

9. Kabat-Zinn J: An outpatient program in behavioral medicine for chronic pain patients based on the practice of mindfulness meditation: theoretical considerations and preliminary results. Gen Hosp Psychiatry 1982, 4:33-47.

10. Bohlmeijer E, Prenger $R$, Taal E, Cuijpers P: The effects of mindfulnessbased stress reduction therapy on mental health of adults with a chronic medical disease: a meta-analysis. J Psychosom Res 2010, 68:539-544

11. Chiesa A, Serretti A: Mindfulness-based stress reduction for stress management in healthy people: a review and meta-analysis. $J$ Altern Complement Med 2009, 15:593-600.

12. Hofmann SG, Sawyer AT, Witt AA, Oh D: The effect of mindfulness-based therapy on anxiety and depression: a meta-analytic review. J Consult Clin Psychol 2010, 78:169-183.

13. Morone NE, Greco CM, Weiner DK: Mindfulness meditation for the treatment of chronic low back pain in older adults: a randomized controlled pilot study. Pain 2008, 134:310-319.

14. Wong SY, Chan FW, Wong RL, Chu MC, Kitty Lam YY, Mercer SW, Ma SH: Comparing the effectiveness of mindfulness-based stress reduction and multidisciplinary intervention programs for chronic pain: a randomized comparative trial. Clin J Pain 2011, 27:724-734.

15. Sadlier M, Stephens SD, Kennedy V: Tinnitus rehabilitation: a mindfulness meditation cognitive behavioural therapy approach. J Laryngol Otol 2008, 122:31-37.

16. Philippot P, Nef F, Clauw L, Romree M, Segal Z: A randomized controlled trial of mindfulness-based cognitive therapy for treating tinnitus. Clin Psychol Psychother 2012, 19(5):411-419. doi:10.1002/cpp.756. Epub 2011 May 12

17. Hesser H, Gustafsson T, Lunden C, Henrikson O, Fattahi K, Johnsson E, Westin VZ, Carlbring P, Maki-Torkko E, Kaldo V, Andersson G: A randomized controlled trial of internet-delivered cognitive behavior therapy and acceptance and commitment therapy in the treatment of tinnitus. J Consult Clin Psychol 2012, 80:649-661.

18. Westin VZ, Schulin M, Hesser H, Karlsson M, Noe RZ, Olofsson U, Stalby M, Wisung G, Andersson G: Acceptance and commitment therapy versus tinnitus retraining therapy in the treatment of tinnitus: a randomised controlled trial. Behav Res Ther 2011, 49:737-747.

19. Holl M: Die Tinnitus-Atemtherapie: So gehen Sie aktiv gegen Ihr Ohrgeräusch vor. Hannover: Schluetersche; 2011.

20. Kleinjung T, Fischer B, Langguth B, Sand P, Hajak G, Dvorakova J, Eichhammer $P$ : Validation of the german-version tinnitus handicap inventory (THI). Psychiatr Prax 2007, 34:140-142.

21. Goebel G, Hiller W: The tinnitus questionnaire. A standard instrument for grading the degree of tinnitus. Results of a multicenter study with the tinnitus questionnaire. HNO 1994, 42:166-172.

22. Beck AT, Steer RA: Internal consistencies of the original and revised beck depression inventory. J Clin Psychol 1984, 40:1365-1367.

23. Landgrebe M, Zeman F, Koller M, Eberl Y, Mohr M, Reiter J, Staudinger S, Hajak G, Langguth B: The tinnitus research initiative (TRI) database: a new approach for delineation of tinnitus subtypes and generation of predictors for treatment outcome. BMC Med Inform Decis Mak 2010, $10: 42$

24. Huck SW, McLean RA: Using a repeated measures ANOVA to analyze the data from a pretest-posttest design: a potentially confusing task. Psychol Bull 1975, 82:511-518.

25. Van Breukelen GJ: ANCOVA versus change from baseline: more power in randomized studies, more bias in nonrandomized studies [corrected] J Clin Epidemiol 2006, 59:920-925.

26. Vickers AJ, Altman DG: Statistics notes: analysing controlled trials with baseline and follow up measurements. BMJ 2001, 323:1123-1124.

27. Kleinjung $T$, Eichhammer P, Landgrebe M, Sand P, Hajak G, Steffens T, Strutz $J$, Langguth B: Combined temporal and prefrontal transcranial magnetic stimulation for tinnitus treatment: a pilot study. Otolaryngol Head Neck Surg 2008, 138:497-501.

28. Biesinger E, Kipman U, Schatz S, Langguth B: Qigong for the treatment of tinnitus: a prospective randomized controlled study. J Psychosom Res 2010, 69:299-304.

29. Veehof MM, Oskam MJ, Schreurs KM, Bohlmeijer ET: Acceptance-based interventions for the treatment of chronic pain: a systematic review and meta-analysis. Pain 2011, 152:533-542.

30. Chiesa A, Serretti A: Mindfulness based cognitive therapy for psychiatric disorders: a systematic review and meta-analysis. Psychiatry Res 2011, 187:441-453.

31. Kerr CE, Jones SR, Wan Q, Pritchett DL, Wasserman RH, Wexler A, Villanueva JJ, Shaw JR, Lazar SW, Kaptchuk TJ, et al: Effects of mindfulness meditation training on anticipatory alpha modulation in primary somatosensory cortex. Brain Res Bull 2011, 85:96-103.

32. Weisz N, Dohrmann K, Elbert T: The relevance of spontaneous activity for the coding of the tinnitus sensation. Prog Brain Res 2007, 166:61-70.

33. Dohrmann K, Weisz N, Schlee W, Hartmann T, Elbert T: Neurofeedback for treating tinnitus. Prog Brain Res 2007, 166:473-485.

34. Weisz N, Langguth B: Cortical plasticity and changes in tinnitus: treatment options. HNO 2010, 58:983-989.

35. Landgrebe M, Langguth B, Rosengarth $\mathrm{K}$, Braun $\mathrm{S}$, Koch A, Kleinjung T, May A, de Ridder D, Hajak G: Structural brain changes in tinnitus: grey matter decrease in auditory and non-auditory brain areas. Neurolmage 2009, 46:213-218.

36. Vanneste S, Plazier M, der Loo E, de Heyning PV, Congedo M, De Ridder D: The neural correlates of tinnitus-related distress. Neurolmage 2010, 52:470-480 
37. Giraud AL, Chery-Croze S, Fischer G, Fischer C, Vighetto A, Gregoire MC, Lavenne F, Collet L: A selective imaging of tinnitus. Neuroreport 1999, 10:1-5.

38. Lanting $C P$, de Kleine $E$, van Dijk $P$ : Neural activity underlying tinnitus generation: results from PET and fMRI. Hear Res 2009, 255:1-13.

39. Holzel BK, Ott U, Hempel H, Hackl A, Wolf K, Stark R, Vaitl D: Differential engagement of anterior cingulate and adjacent medial frontal cortex in adept meditators and non-meditators. Neurosci Lett 2007, 421:16-21.

40. Tyler RS, Oleson J, Noble W, Coelho C, Ji H: Clinical trials for tinnitus: study populations, designs, measurement variables, and data analysis. Prog Brain Res 2007, 166:499-509.

doi:10.1186/1472-6882-12-235

Cite this article as: Kreuzer et al:: Mindfulness-and body-psychotherapybased group treatment of chronic tinnitus: a randomized controlled pilot study. BMC Complementary and Alternative Medicine 2012 12:235.

\section{Submit your next manuscript to BioMed Central and take full advantage of:}

- Convenient online submission

- Thorough peer review

- No space constraints or color figure charges

- Immediate publication on acceptance

- Inclusion in PubMed, CAS, Scopus and Google Scholar

- Research which is freely available for redistribution 